\title{
Sizes and Some Features of Luminous Sources Associated with the 1995 Hyogo-ken Nanbu Earthquake
}

\author{
Tameshige Tsukuda \\ Earthquake Research Institute, The University of Tokyo, Bunkyo-ku, Tokyo 113, Japan
}

\begin{abstract}
Sources of luminescence and their buildup processes accompanying the 1995 Hyogo-ken Nanbu earthquake of $M 7.2$ are studied based on pieces of information obtained mainly by interviewing eyewitnesses. Gross forms of relatively large-scale luminous sources are roughly classified into four types: lightning with zigzag lines, a swelling shield-shaped source, an upward-extending fan-shaped source, and a belt of lights. The last one includes an arc-like source. Each source is predominantly in tones of either colorless-white, blue or orange-color. This paper presents 23 spottings, distributed as wide as $50 \mathrm{~km}$ from the epicenter of the mainshock near Kobe City. Along with these spottings, some local flashing events were reported. The upper limit of the height of several sources was able to be estimated as less than $200 \mathrm{~m}$ above the ground. The linear dimension of the horizontal extent ranged from about 1 to $8 \mathrm{~km}$. The luminance was estimated to be more than an order of $10^{3} \mathrm{~cd} / \mathrm{m}^{2}$ for an arc-like orange colored source at the eastern part of the aftershock area. Not a few sources were glittering more intensely than this case. According to most of the eyewitnesses, the luminosity started from ground level on land, suggesting that discharge processes of the polarized electricity in near-surface rocks may be the primary driving force of the luminescence. However, electricity charged in the air should be also responsible to some luminous phenomena, especially a kind of lightning above the sea. Fog or dust was observed in the air in the region around Nishinomiya City, east of Kobe, preceding the quake, which might have played the role of an effective electrical conductor in glow discharge.
\end{abstract}

\section{Introduction}

On January 17, 1995, a shallow large earthquake of $M 7.2$ struck Kobe, a representative port city of Japan, and neighboring cities and towns at 05:46 local time. The author made a field survey of various kinds of phenomena accompanying this destructive inland earthquake for 20 days immediately after the quake, and then continued studies several times intermittently for an additional 20 days, visiting many places to search for eyewitnesses of the phenomena and making on-the-spot surveys concerning observations (Tsukuda, 1995a). This paper is a preliminary report on luminous phenomena presumably related to the southern Hyogo earthquake, following and improving a previous report (Tsukuda, 1995b).

As the quake occurred very early in the morning, it was dark enough for people to be clearly conscious of the luminescence if they were outside. However, the number of eyewitnesses was quite limited: they were mostly drivers of automobiles, newspaper delivery persons, early morning walkers or joggers. The major survey items were: (1) location of observation point, (2) approaching direction of light, (3) view image, (4) horizontal range and height of the luminous source, (5) color of the light, (6) time of occurrence and lifetime, and (7) visibility or circumstances at the observation spot.

Luminous phenomena accompanying earthquakes have been reported from ancient times as found in historical documents (e.g., Tributsch, 1985). A systematic research on this phenomenon was made by Musha (1931) based on a questionnaire survey for the 1930 northern Izu earthquake of M7.0. Terada (1931) reviewed previous studies on seismic luminescence and presented a theory on the mechanism of this phenomenon. Frequent observations of luminescence were reported at the time of the Matsushiro earthquake swarm in Nagano, central Japan, during a period of high activity from 1965 to 1967 (Japan Meteorological Agency, 1968;

Received July 27, 1995; Accepted September 19, 1996 
Yasui, 1968). The locations of the light sources were confined to a narrow region within $10 \mathrm{~km}$ in diameter. A resident succeeded in taking photographs of the light five times or more. After that time, seismic luminescence has been scarcely reported except for a few examples (Yasui, 1971, 1972; Tsukuda et al., 1991).

The purpose of this paper is to determine the exact locations of the light sources, to make clear the sizes and forms of the individual sources with such properties as color tone and luminance, and to estimate their buildup processes. Therefore, witnesses that did not observe any phenomenon are also needed to verify the extent of a source area and spacing of the source locations. Measurements and analyses from this point of view have been treated insufficiently in previous studies.

\section{Classification of the Luminous Sources and Their Locations}

Original data sources in this study are reports by people, which were mainly obtained by interview. The reports were often suspicious, questionable, or vague. To raise the accuracy and reliability of data, various examinations were made: repeated confirmation of the reports, inspection of the circumstances of eyewitnesses' observation spots, comparisons between reports of different persons and so on. This research is currently in progress and requires a long time to obtain sufficient data; therefore, the results in this paper will be revised at a later date.

It is possible to distinguish two different modes of luminous source: a very small flashing source and a large-scale source with a long lifetime of more than several seconds. The former is like a strobe flash and its size may be within tens of meters. The

(1)

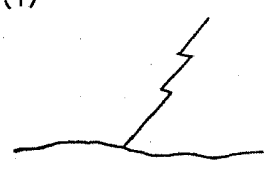

(3)
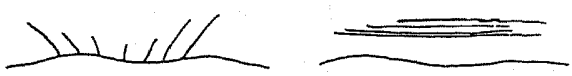

Fig. 1. Types of light source: (1) lightning, (2) shield, (3) fan, and (4) belt. latter looks like a compound of flashing lights and a glittering gas volume. Hereafter, the author refers to the sources of this mode as "cumulative sources." The distant views of cumulative sources have various shapes. They are roughly classified into four types: (1) lightning, (2) shield-like, (3) fan-like, and (4) belt-like sources.

A type (1) source is a compound of zigzag light lines like a lightning bolts. The second source (2) is a glittering air volume covering the ground. The upper boundary is cleary seen with a rise in its central part. In some cases, the source has a flow of light creeping on the ground in its peripheral zone. Type (3) is described as an upward-extending source which looks like a fan. The type (4) source is seen as a light belt running horizontally. Figure 1 is an illustration of the above typical shapes. Disclosed cumulative sources are listed in Table 1 with their properties. Their locations are also plotted in a map shown in Fig. 2. There are also uncertain events without specification of luminous forms. Even such events (Nos. 6, 7, and 17 in Fig. 2 and Table 1) can be located accurately to within several kilometers judging from reports of viewing directions and visible ranges.

The light of a type (1) source seems to be lowintensity lightning without a peal of thunder. The most marked events of this type took place in the Straits of Akashi close to the epicenter of the main shock, as will be mentioned in Sec. 3 (No. 21 in Table 1 and Fig. 2). The other source types were sometimes accompanied by extremely local lightning or some kind of sparks. The type (2) source is considered to be a standard for luminescence or the most typical type of event; it looks like an illuminated body in the air close to the ground. An isolated luminous source with a size within 1 or $2 \mathrm{~km}$ takes this form. The duration time of this luminescence is more than several seconds. A proprietor of a newspaper shop, in Tarumi Ward, Kobe, observed the buildup process of a light source located about $4 \mathrm{~km}$ east of the shop, at the eastern foothills of Mt. Yokoo, Suma Ward, Kobe (No. 13). In the early stages, the light source was low in height and shining colorless or white. Then, an orange-colored core gradually swelled upward several tens of seconds later. The total duration time of luminescence was more than $30 \mathrm{~s}$.

A fan-shaped image was observed from distant places for the source around Nishinomiya and Amagasaki Cities, east of Kobe (No. 9). There are 


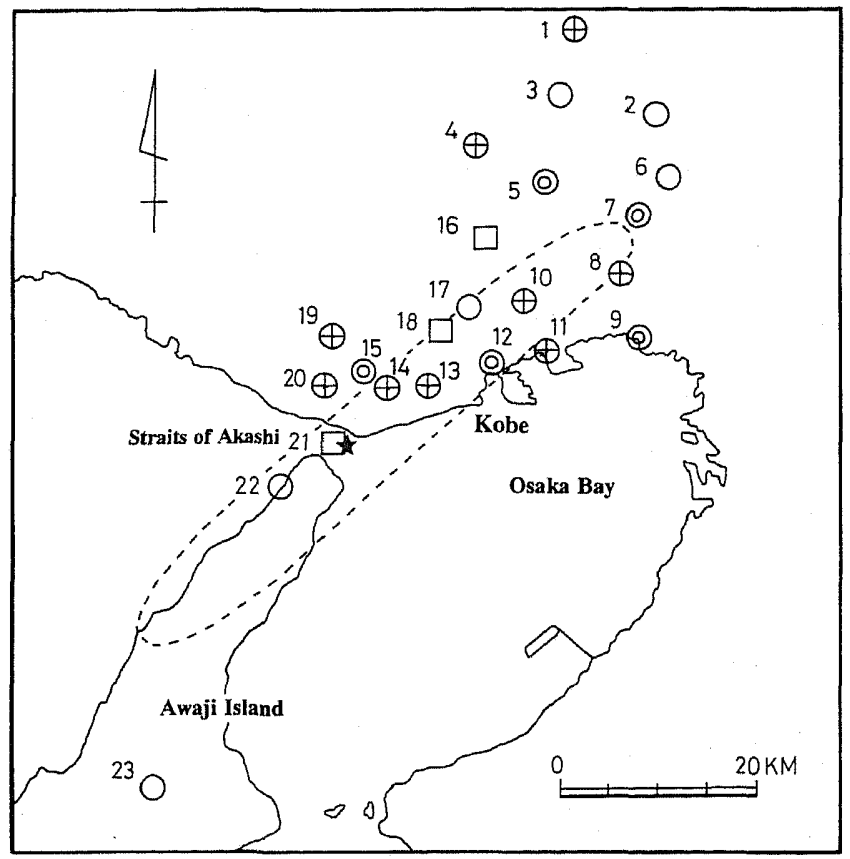

Fig. 2. Distribution of the light sources. Double circle, open circle, and open circle with cross denote blue, colorless, and orange-colored sources, respectively. Sources of lightning type are represented by rectangles. The source number in Table 1 is attached to the corresponding source. Aftershock area of the Hyogo-ken Nanbu earthquake is bordered by a broken line. The star indicates the mainshock epicenter.

some eyewitnesses who observed lights just around them in the above region. It is quite difficult to distinguish individual sources. When a number of sources of various types took place simultaneously or successively in a restricted region, it is scarcely possible to draw a simple picture of the luminous body. The extending fan-shaped distant view image may be an example of this type. Another report of this fan-shaped image is event No. 3 .

A typical example of a type (4) source was observed in downtown Kobe: A bluish light spread horizontally at a high level of $150-200 \mathrm{~m}$ above sea level (No. 12). There were also arc-like belts of light (Nos. 8, 14), an event which was accompanied by a light streamer creeping along the ground for event No. 19, which was mainly classified as a shield-type event, and a similar streamer was observed at the peak of Mt. Rokko, Kobe (No. 10).

Locally small-scale flashing of light was observed in some places. A junior high school boy and his family members saw white or slightly yellowish flashes of light three times successively from a fissure in the ground generated by the mainshock, while immediate aftershocks were occurring in succession, at the slope of Mt. Rokko, Higashi-Nada Ward, eastern Kobe City. A small bluish light ball, elongated horizontally, occurred inside a bedroom on the first floor of a two-story house during large shaking of the mainshock in eastern Akashi City, west of Kobe.

Most of the luminescence was generally in white color with some weak tints. Some light sources had a clear, predominant color: blue or orange. The "orange color" here means a reddish orange like a boiled lobster.

The luminous sources were distributed over a wide area from the southern part of Awaji Island in the south to the northern part of Inagawa Town, Hyogo Prefecture, in the north, about $50 \mathrm{~km}$ from the epicenter of the main shock. The eastern end of the distribution was around Amagasaki City, the western part of Osaka Prefecture. The western limit was not clear, and further investigations are needed. The sources were separated from each other by distances of 5-10 km. The density of the distribution is high around the western part of Kobe City, close 
Table 1. Locations and properties of the cumulative light sources directly accompanying the Hyogo-ken Nanbu earthquake.

\begin{tabular}{|c|c|c|c|c|c|c|}
\hline No. & Region & Weather & $\begin{array}{l}\text { Origin } \\
\text { time* }\end{array}$ & $\begin{array}{c}\text { Duration } \\
\text { time }(\mathrm{s})\end{array}$ & Color & Mode or shape \\
\hline 1 & Northern Inagawa $\mathrm{T}$. & Cloudy & (1) & & Slightly red & Shield shape \\
\hline 2 & $\begin{array}{l}\text { Southern Inagawa } T \text {. } \\
\text { (border of Kawanishi C.) }\end{array}$ & Cloudy & (3) & $2-3$ & Colorless white & Shield shape \\
\hline 3 & Northern Sanda C. & Slightly cloudy & (1) & $5-10$ & Colorless white & Shield or fan \\
\hline 4 & $\begin{array}{l}\text { Southwestern Sanda C. } \\
\text { or northern Kobe C. }\end{array}$ & Light rain & (1) & $3-5$ & Orange color & Shield shape \\
\hline 5 & Northern Kobe C. & & (3) & $1-2$ & Dimly blue & Shield shape \\
\hline 6 & Kawanishi $\mathrm{C}$. & Cloudy & (1) & $2-3$ & Yellowish white & \\
\hline 7 & Takarazuka C. & & (3) & 1 & Blue-white & \\
\hline 8 & $\begin{array}{l}\text { Northern Nishinomiya C. } \\
\text { (east of Mt. Kabuto) }\end{array}$ & Cloudy & (1) & $3-4$ & Orange color & Arc shape \\
\hline 9 & Southern Nishinomiya C. & Cloudy & (3) & & Bluish white & Fan shape \\
\hline 10 & On the ridge of $\mathrm{Mt}$. Rokko & Light snow & (4) & $1-2$ & Orange color & Horizontal belt \\
\hline 11 & $\begin{array}{l}\text { Higashi-nada and } \\
\text { Nada wards, Kobe C. }\end{array}$ & & (2) & $1-2$ & Red or pink & Belt-like \\
\hline 12 & $\begin{array}{l}\text { Chuo and Hyogo wards, } \\
\text { Kobe C. }\end{array}$ & Cloudy & (1) & $2-3$ & Blue or green & Layer or belt \\
\hline 13 & $\begin{array}{l}\text { Suma Ward, Kobe } \\
\text { (east of Mt. Yokoo) }\end{array}$ & Cloudy & (2) & $>30$ & Orange color & Shield shape \\
\hline 14 & $\begin{array}{l}\text { Tarumi Ward, Kobe } \\
\text { (Manabiga-oka) }\end{array}$ & Light snow & $(2)$ & $4-5$ & Orange cölor & Arc or belt \\
\hline 15 & $\begin{array}{l}\text { Tarumi Ward, Kobe } \\
\text { (Tamon-cho) }\end{array}$ & & (2) & $2-3$ & Blue & Shield shape \\
\hline 16 & $\begin{array}{l}\text { Kita Ward, Kobe } \\
\text { (Arino-cho) }\end{array}$ & Cloudy & (3) & $1-2$ & White-blue & Lightning \\
\hline 17 & $\begin{array}{l}\text { Kita Ward, Kobe } \\
\text { (Koryo-cho) }\end{array}$ & & & & & \\
\hline 18 & $\begin{array}{l}\text { Kita Ward, Kobe } \\
\text { (north of Mt. Kikusui) }\end{array}$ & Cloudy & (2) & $1-2$ & White-blue & Lightning \\
\hline 19 & $\begin{array}{l}\text { Nishi Ward, Kobe } \\
\quad \text { (south of Seishin New T.) }\end{array}$ & Light snow & (1) & $7-10$ & Orange color & Shield shape \\
\hline 20 & Southern Akashi City & Cloudy & (3) & & Orange color & Shield shape \\
\hline 21 & Straits of Akashi & Cloudy & (3) & $2-3$ & Colorless color & Lightning \\
\hline 22 & $\begin{array}{l}\text { Nojima, Hokudan T., } \\
\text { Awaji Island }\end{array}$ & Light rain & (3) & $1-2$ & Yellowish white & Flash \\
\hline 23 & Midori $\mathrm{T}$. & Light rain & (2) & $1-2$ & Colorless & White flash \\
\hline
\end{tabular}

* The origin time is according to the ground motion processes: (1) during rumbling noises preceding severe ground motions, (2) immediately before the first shock, (3) during shocks or shaking, and (4) after severe shaking.

to the epicenter of the mainshock. Nearly $40 \%$ of the sources were those of orange color. Bluish sources were limited in number. The zone of orange sources and that of other colors of sources were roughly aligned alternately in parallel with the trend of the aftershock area.

\section{Estimation of the Size of the Source}

This section describes how the source sizes were estimated, showing some typical examples. The spot of the first example is located in a city area (No. 12 in Fig. 2 and Table 1). A layer of bluish light was seen over buildings of the central city area of Kobe, which initiated with rumbling noises prior to severe shocks of strong ground motion. Tall buildings blocked the visibility of observers on the street. The author searched for observers from high level positions such as high-rise hotel build- 
ings, but the effort was in vain. Fortunately, there were several very informative observers who carefully watched the luminescence.

One of the eyewitnesses of this light was a man driving his car toward the west on an elevated expressway which toppled on its side just after the quake. The town ahead was illuminated with blue or green lights.

Another witness arrived at his company located at the northwestern end of Port Island, one of the large artificial islands in Kobe, when he saw the blue light running from west to east over the city area north of the island. He reported to have seen a thin-layered light source at an angle higher than that of the apparent ranges of Mt. Rokko. The source layer should be $150-200 \mathrm{~m}$ above sea level if the source is located within the central city area.

The other eyewitness was walking along a trail of Mt. Takatori, its peak being $328 \mathrm{~m}$ above sea level, at the time of the quake. He heard noises around him and saw a blue light spreading over the city at the same level of his eyes. The altitude of the observation point was about $170 \mathrm{~m}$. This level is consistent with that estimated by the evidence given by the witness at Port Island. Figure 3 shows the geometry of this source. Its horizontal range is probably not less than $3 \mathrm{~km}$ in diameter. A more exact extent will be made clear by further surveys. The flat top of the light source characterizes this luminescence.
The second example shows a source observed from one side: a spot on the slope of a hill. One of the luminous sources observed widely in the eastern part of the aftershock area was located at the eastern foot of Mt. Kabuto, a cone peak of $309 \mathrm{~m}$ in altitude at the eastern end of the Rokko mountain range (No. 8). A lady delivering newspapers house to house observed an orange-colored light in the direction of northwest from the fourth floor terrace of an apartment house building. The light source traced an arc-like image of an arch-type bridge. Due to full darkness, it was difficult to locate in reference to the scenery. However, the observed height and range of the arc suggest its location as in front of the peak of Mt. Kabuto. A topographic consideration leads to the arc being $1 \mathrm{~km}$ wide and about $200 \mathrm{~m}$ high above sea level. Figure 4 shows an illustrated image with a photograph of the landscape viewed from the observation point. Some observers, walking on a street located $7 \mathrm{~km}$ east of the source, saw it as a white body with orange streamers. Observers from the opposite direction, on the hill side of the Rokko mountain range, have not yet been located.

The third example presents a source on a relatively flat terrain in the western part of Kobe City (No. 19). Figure 5 shows the location of this luminous source and the distribution of the observation points of eyewitnesses. A fireman who was walking his dog encountered a series of phenomena associated with

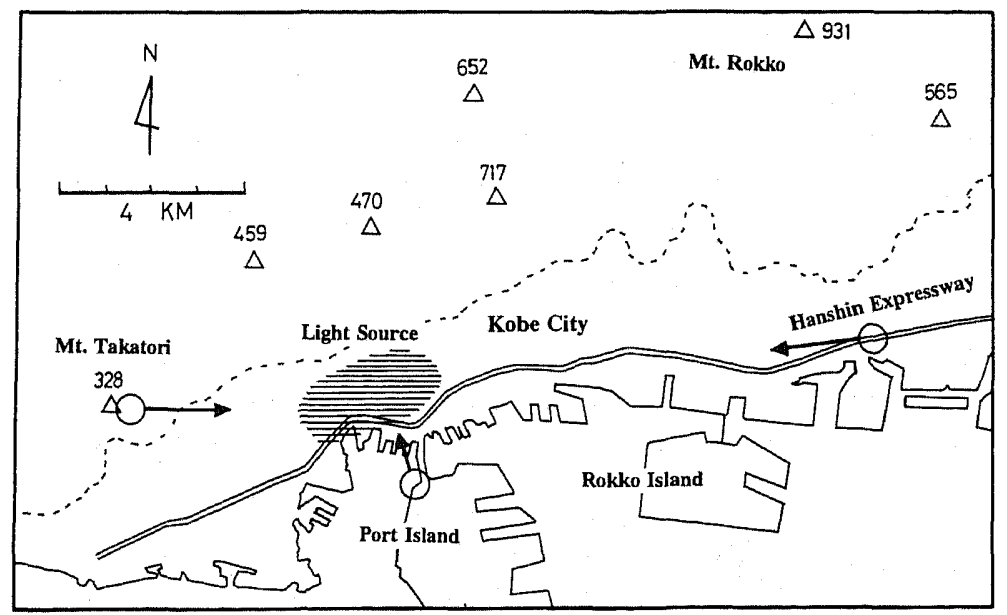

Fig. 3. The blue light source at the center of Kobe City, the shaded zone on the map. Open circles denote the observation points. The arrows indicate the direction of light received by the observer. The dotted line shows the border of the city area in the south and the northern mountainous area. Some peaks are shown by triangles with heights in meters above sea level. 

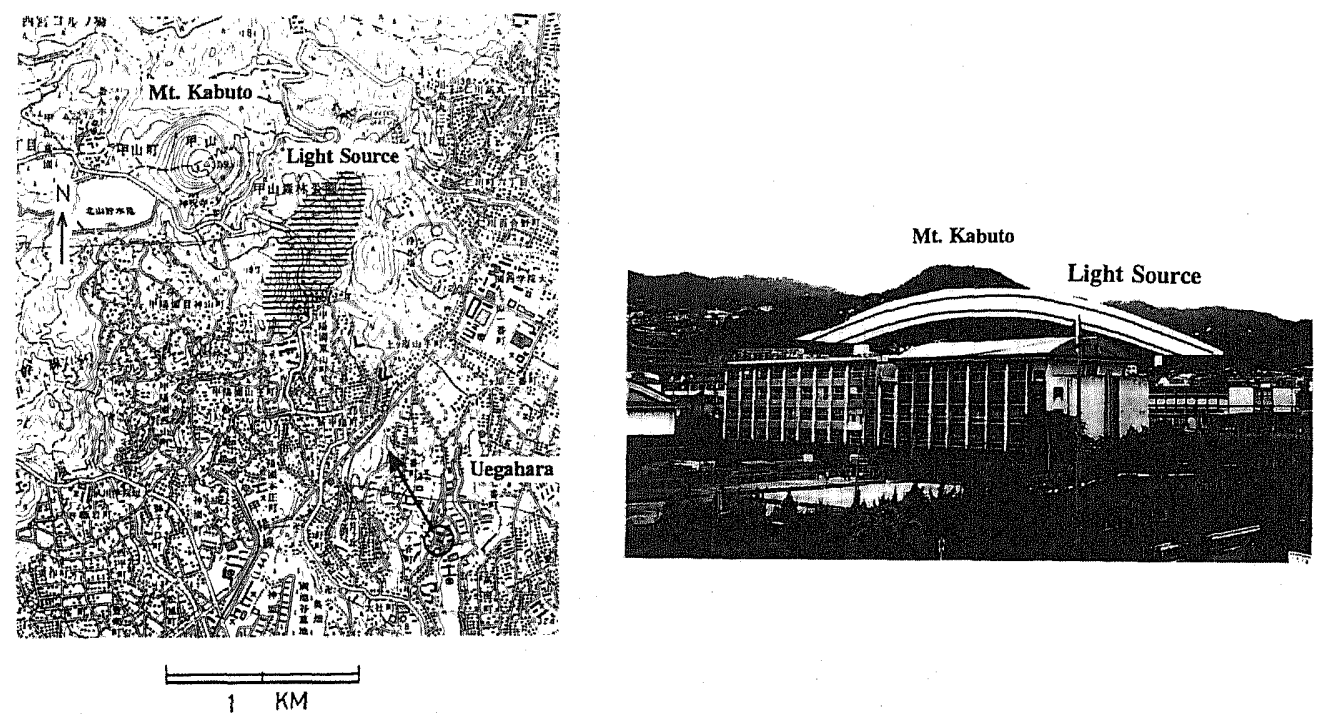

Fig. 4. (Left) The orange-colored light source at the foot of Mt. Kabuto, Nishinomiya City, the shaded zone on the map. (Right) Landscape photograph viewed from the observation point at Uegahara, which is shown on the map by an open circle with an arrow indicating the light direction.

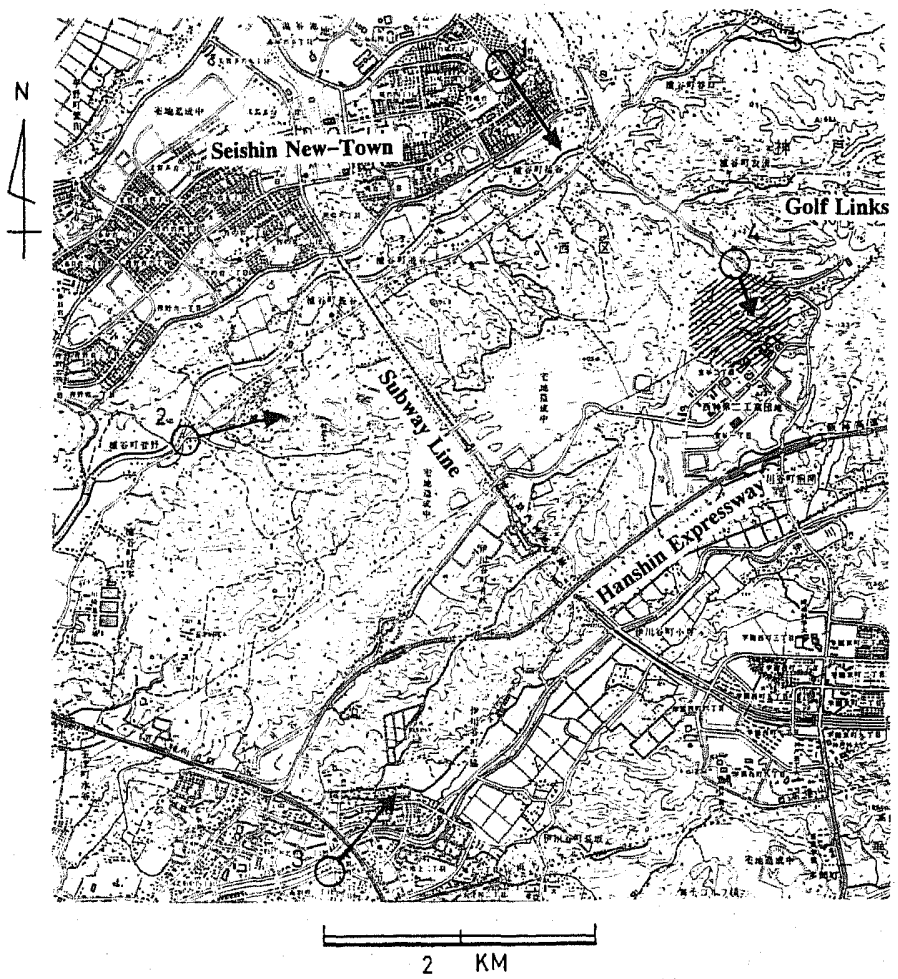

Fig. 5. The orange-colored light source in the western part of Kobe City, the shaded zone on the map. Open circles denote the observation points. The arrows indicate the direction of light received by the observer. The No. 1 point is the site where a belt-like colorful light creeping along the ground was observed. 
the quake (Spot No. 1 in Fig. 5). Firstly, he noticed a strange sound and multi-colored light streamers, particularly orange-colored belts, running just above the road from north to south for several seconds. Then the light source swelled upward far beyond the south. A man driving his car to work also saw the swelling light source at a point close to the center of the light (Spot No. 4). This source was located $2 \mathrm{~km}$ south of the spot where the fireman saw the tail of the light preceding it. The driver stopped his car after the shock of the quake when he saw the light. The duration time was $4-5 \mathrm{~s}$. The elevation change in topography in this area is smooth, within tens of meters, and there are few tall buildings, so it would be hard for people to overlook a large-scale luminous source like this outside. There were some eyewitnesses of this light from a far distance (Spot Nos. 2 and 3). Thus, the observed cumulative light source was a unique one, covering the whole area shown in the map.

The fourth example is concerned with a wide source area. There were a few people who saw strong beams of light close to themselves in southern Nishinomiya and Amagasaki Cities (No. 9). A high school teacher observed this light source when he was walking his dog south of Hattori Green Park, Toyonaka City, Osaka Prefecture. The light source covered an angle as wide as $45^{\circ}$. It is probable that the center of the source was located around the southeastern part of Nishinomiya City, and the observation distance was 8 to $10 \mathrm{~km}$. Then, the diameter of the source is estimated to have been 6 to $8 \mathrm{~km}$. This estimate is based on an observation from a far distance. There may be some local sources, close-by observers, which the author is now searching for.

The last example shows luminescence above the sea. The source in the Straits of Akashi was composed of three zigzag lines of lightning (No. 21). The three lines appeared successively from west to east. The extent of the region was within several kilometers. This estimation is based on a report by a worker at Iwaya Harbor, on northeastern Awaji Island. However, this witness could not describe the source. A ferryboat was approaching Akashi Port at a distance of $1 \mathrm{~km}$, and the captain and his crew members on the bridge never noticed lightning north in the direction of land, Akashi City. The lightning must have occurred behind the ship or in the midst of the strait. Moreover, a boy delivering newspapers recognized two zigzag lines southward in the southern part of Akashi City.

\section{Estimation of the Origin Time and Duration Time of Luminescence}

Almost all the reports are on luminescence simultaneous with the mainshock. However, the occurrence times are slightly different from event to event. Reference times corresponding to the ground motion processes of the quake are necessary, as there are no exact records of time. Before strong ground motion at the time of the earthquake, people heard peculiar sounds or noise around them. This is called a rumbling of the earth or underground noise. The forerunning noise lasted at least several seconds in the region of the seismic source.

Some occurrences of luminescence occurred during the ground rumbling stage. Another group was observed during strong ground motions. There are also luminescences which started after the major strong motions had finished. One of them was observed at the ridge of the Rokko mountain range, an orange-colored light belt running from east to west and shining dimly. A young lady in a car witnessed this when she and her friend stopped to rest at a parking area on top of the mountain range before arriving at their workplace, a hotel. Woken from sleep by the severe quake, she saw the belted light when the strong tremor had almost attenuated about $10 \mathrm{~s}$ after the first large shock.

The lightning-like flashes finished instantly, within a second. The luminescence by other cumulative sources was maintained more than several seconds. There is a case where the luminescence was maintained more than $10 \mathrm{~s}$. Reported origin times and duration times are listed in Table 1.

In addition to co-seismic luminescence sightings, some pre-seismic observations were reported. A variety shop proprietress in the middle of the Inagawa Town area observed a dimly illuminated col of southern hills after midnight. The light was rather strong at the col and the upper part of the light source was colored red or pink. She did not record the exact occurrence time. The duration time was several tens of seconds or more. The illuminated part of the sky was reportedly below the peaks of the hill range. The source should have been located in a mountainous area in the southern part of Inagawa Town since that the illuminated sky travelled upward at an angle of elevation less than $2.7^{\circ}$. It can be assumed that the height of the source was less than $200-300 \mathrm{~m}$ above the ground, as found 
in several examples in the previous section.

Meanwhile, a newsman observed a reddish dimly bright sky in Suma Ward, Kobe City, several tens of seconds or more before the earthquake. The eyewitnesses of such precursory luminous phenomena have been very few until now. The author is now searching for additional eyewitnesses for these events to confirm whether they are possible precursory luminous events for the Hyogo-ken Nanbu earthquake.

As for a possible preparatory phenomena related to the luminescence, fog or dust was reportedly observed in the air in the region around Nishinomiya City, east of Kobe, from at least several tens of minutes before the quake. The gas body was reported to have been somewhat illuminated.

\section{Estimation of the Luminance of the Source}

As a light source is like a gas volume rather than a point source, luminance is used to evaluate the brightness, which is defined by luminous intensity per unit area of the source surface. It has been said that the light was as bright as if it were daytime when observed closely. When the size of the source and the illuminance at the observation site are known, the luminance can be estimated.

People observed the moonlight just before the earthquake. This should be applied as a reference of the illuminance of the light sources. The phase of the moon at the time of the event was 15.5, almost a full moon. The light at the foot of Mt. Kabuto, Nishinomiya City, was observed by two ladies at a point $7 \mathrm{~km}$ east of the source. They said that the light appeared brighter than the full moon, which had been observed clearly before the quake. Since the illuminance of a full moon is $0.21 \mathrm{x}$, the luminous intensity and luminance of the light source should be at least $9.8 \times 10^{6} \mathrm{~cd}$ and $9.8 \times 10^{2} \mathrm{~cd} / \mathrm{m}^{2}$, provided that the side area of the source observed was $100 \mathrm{~m} \times 100 \mathrm{~m}$.

Another reference of the light source is the illumination equipment for night games at baseball stadiums, of which the light is familiar to people. One eyewitness (No. 4 in Fig. 5) of the light source in the western Kobe (No.19 in Table 1) reported the brightness was slightly weaker than the light of a stadium.

For instance, the Green Stadium Kobe has 6 sets of lighting panels. The largest set has 90 floodlights (using two types of lamps with almost the same luminous flux). A lamp has a luminous flux of about
$10,000 \mathrm{~lm}$. Therefore, the total luminous intensity and luminance are calculated as $1.4 \times 10^{6} \mathrm{~cd}$ and $1.9 \times 10^{4} \mathrm{~cd} / \mathrm{m}^{2}$, respectively, since the area of the panel is $4.5 \mathrm{~m} \times 16.5 \mathrm{~m}$.

This can be used as a reference of the luminance. The illuminance by this light panel at a distance of $100 \mathrm{~m}$ is as much as $140 \mathrm{~lx}$. If a source has the same luminance and an effective source area of $100 \mathrm{~m} \times$ $100 \mathrm{~m}$, then the illuminance at a distance of $100 \mathrm{~m}$ would amount to $1.9 \times 10^{4} \mathrm{Ix}$. This value is far beyond that of daylight, which is about 2,000 lx.

A source which emits light as bright as daylight should have a luminance of $2 \times 10^{3} \mathrm{~cd} / \mathrm{m}^{2}$ provided that the source has an effective area of $100 \mathrm{~m} \times 100 \mathrm{~m}$ and the distance of the observation point is $100 \mathrm{~m}$. The value of the luminance is comparable to the previous estimate of the orange-colored source.

\section{Discussion}

The classification of light sources and zonal configuration of orange sources and others along the trend of the aftershock area may suggest luminescence is closely related to seismogenic processes. It should be noted that the luminous sources were distributed widely beyond the region of seismic and/or active faults. It seems that the fault fissure is not the main cause of luminescence. The mode of ground motions and crustal movements associated with the quake should be studied in connection with luminous phenomena. This is beyond the purpose of this paper.

The heights of the sources of the luminous phenomena disclosed in this study are not more than $200 \mathrm{~m}$ above the ground. Even for the lightning-type sources, the zigzag lines were reportedly observed very low in height as compared with those in thunderstorms. Consequently, luminescence takes place in the air just above the ground.

It is probable that the light comes from the discharge of electricity. The luminous body is likely air gas just above the ground. When the electric current is excessive, the light source forms zigzag lines. When the path of the current is short and small, it will make a brief shot of flash. Weak current through ionized gas causes a glow discharge and dim glooming light. The last of which can continue for a long time. Most of the cumulative sources had a duration time of discharge of more than several seconds.

There is a possibility of sonoluminescence at the time of rumbling of the earth. The abrupt change 
of air pressure produces the excitation of atoms and emits light. A review of the study of sonoluminescence is given by Crum (1994). The mechanism of the rumbling noise itself has never been solved yet. Why do such high-frequency vibrations take place preceding bodily sensitive lower-frequency seismic waves? Usually high-frequency waves attenuate more quickly than those of low frequency through propagating the medium. The frontier of the initial seismic waves likely make new sources of seismic waves which contain many high-frequency components. The seismic sources are considered to be newly produced small cracks around the frontier of the initial waves, which emit high-frequency seismic waves.

Tributsch (1978) proposed an aerosol hypothesis for interpreting the various precursory phenomena of earthquakes. The aerosol comes from underground before an earthquake carrying an electric charge, and serve as a conductor of electric current. This aerosol may support a glow discharge type of luminescence. Some early risers saw an unusual fog or dust just before the earthquake. Some eyewitnesses seemed to be very close to the sources and said to have felt electricity. Further studies are needed to determine whether or not this dust is a kind of aerosol emitted from underground with high-frequency ground vibrations.

In connection with the aerosol hypothesis, a tentative study on the electric field in the air just above the ground was conducted by Kondo (1966) at the time of the Matsushiro earthquake swarm in central Japan. Unfortunately, no luminescence event was reported during the 2 months he was conducting his experiment. Notwithstanding, very interesting data on electric potential changes were obtained. The atmospheric potential gradients were often decreased in accordance with seismic activities. The decrease might be partly due to the increased concentration of ionized gases.

Even if the aerosol carries charges, a big problem is where the polarized electric charge was stored underground. Piezoelectric effects of rocks are the most probable primary cause of polarization of electricity underground. In real rocks underground, this electro-mechanical phenomena should be related to microcracks produced in the processes of crustal deformation. The open cracks would be electrically polarized by charge separation processes. A pre-existing weak electric field can be magnified by the relatively static dielectric permittivity inside the cracks, provided they are generated rapidly (Petrenko, 1993). This is a simple model of charge separation. The breaking of chemical bonds generates electric charge as well. Recently, O'Keefe and Thiel (1995) applied their three-dimensional finite difference charge separation model to ice crack experiments, reproducing the electric field wave shape. In order to make a quantitative estimate of the polarized electric charge in the real field of rocks, one of the methods is a field experiment measuring both electric potential and crustal deformation at many points in some target area. One should bear in mind that the flow of groundwater passing through the crack system acts as a conductor of electricity.

For the purpose of predicting earthquakes, the relationship between crustal movements preceding earthquake events and various electromagnetic phenomena which involve seismic luminescence are an important problem. A study of the detailed features of luminous phenomena is fundamentally important to solve this.

In this study, a search for eyewitnesses was made by interviews with people at newspaper shops, public facilities like city offices and fire stations, residences of some target areas, and so on. This inquiry often brings indirect information; some residents have information from other persons. In some cases, much had to be done to reach the actual eyewitness. This inquiry method was almost the only way immediately after the earthquake disaster.

Now that the restoration of damaged cities and towns has accelerated, and the people have recovered more or less to stable daily lives, the author is planning a questionnaire survey by mail to search for persons who might have observed luminescence and other phenomena. Even if the mail method is applied, the interview method will be indispensable for confirming the detailed information and circumstances at the witness site at the time of the event.

\section{Conclusion}

The method of inquiry survey was effectively applied for the identification of the sources of luminescence before, during, and after a large earthquake, the 1995 Hyogo-ken Nanbu earthquake. A rumbling sound preceding strong shaking was regarded as a reference of the occurrence time of luminescence. The occurrence time, lifetime, and size of the source were disclosed for some major 
sources. The sources were widely distributed, reaching as far as $50 \mathrm{~km}$ from the epicenter of the main shock.

A layered bluish light covered the central city of Kobe at a height of $150-200 \mathrm{~m}$ above sea level at the beginning of roaring noise and preceding large ground shaking.

An arc-like orange-colored light source, which was seen as a whitish source with orange-colored stripes from distant places, was observed in the northern part of Nishinomiya City, east of Kobe, as high as about $200 \mathrm{~m}$ at the foot of a hill. The luminance of this source was not less than $10^{3} \mathrm{~cd} / \mathrm{m}^{2}$. Other major sources were considered to have the same level of luminance or more.

Another swelling orange-colored source was identified in the western part of Kobe City, and was accompanied by near-ground dim light in streamers and bands. It took $3 \mathrm{~s}$ or more to buildup the swelling source. Another source of the same kind in Suma Ward, Kobe, had a long lifetime of more than $30 \mathrm{~s}$. Orange-colored sources totaled nearly $40 \%$ of all the sources identified.

This paper is a preliminary report on seismic luminescence; a further study is now going on to make clear more detailed features of the luminous sources.

The author is indebted to hundreds of people for providing valuable information on various kinds of phenomena associated with the Hyogo-ken Nanbu earthquake. Comments given by the referees of this paper were greatly helpful in improving the text.

\section{REFERENCES}

Crum, L. A., Sonoluminescence, Phys. Today, 47, No. 9, 22-29, 1994.

Kondo, G., The variation of the atmospheric electric field at the time of earthquake, Mem. Kakioka Magnet. Observ., 12, 11-23, 1966.
Musha, K., On the luminous phenomena that attended the Idu earthquake, November 26th, 1930, Bull. Earthq. Res. Inst., 9, 177-215, 1931 (in Japanese with English abstract).

O'Keefe, S. G. and D. V. Thiel, A mechanism for the production of electromagnetic radiation during fracture of brittle materials, Phys. Earth Planet. Inter., 89, 127-135, 1995.

Petrenko, V. F., On the nature of electrical polarization of materials caused by cracks. Application to ice electromagnetic emission, Philos. Mag. B., 67, 301-315, 1993.

Terada, T., On luminous phenomena accompanying earthquakes, Bull. Earthq. Res. Inst., 9, 225-255, 1931.

Tributsch, H., Do aerosol anomalies precede earthquake?, Nature, 276, 606-608, 1978.

Tributsch, H., Animals Would Predict Earthquakes (translated version of "Wenn die schlangen erwachen" in German, 1978, by T. Watanabe), Asahi Shinbunsha, Tokyo, 1985 (in Japanese).

Tsukuda, T., Precursors and Prediction of a Large Earthquake, Asahi Shinbunsha, Tokyo, 1995a (in Japanese).

Tsukuda, T., Luminescence associated with the Hyougoken Nanbu earthquake, Earth Monthly, Suppl., No. 13, 184-189, 1995 b (in Japanese).

Tsukuda, T., K. Sakai, S. Hashimoto, M. R. Gheitanchi, H. Suzuki, S. Soltanian, and P. Mozaffari, A field study on various phenomena associated with the 1990 Rudbar, northwest Iran, earthquake of M7.3, Bull. Earthq. Res. Inst., 66, 419-454, 1991 (in Japanese with English abstract).

Yasui, Y., A study on the luminous phenomena accompanied with earthquake (Part I), Mem. Kakioka Magnet. Observ., 13, 25-61, 1968 (in Japanese with English abstract).

Yasui, Y., A study on the luminous phenomena accompanied with earthquake (Part II), Mem. Kakioka Magnet. Observ., 14, 67-78, 1971 (in Japanese with English abstract).

Yasui, Y., Seismo-luminous phenomena at Santa Rosa, Mem. Kakioka Magnet. Observ., 15, 81-86, 1972 (in Japanese with English abstract). 